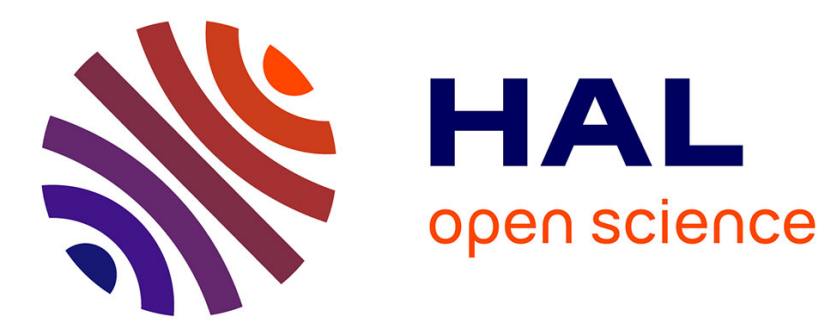

\title{
Sustainability in Publishing: An Open Access Publisher's View \\ Martyn Rittman
}

\section{To cite this version:}

Martyn Rittman. Sustainability in Publishing: An Open Access Publisher's View. ELPUB 2018, Jun 2018, Toronto, Canada. 10.4000/proceedings.elpub.2018.9 . hal-01816816

\section{HAL Id: hal-01816816 https://hal.science/hal-01816816}

Submitted on 15 Jun 2018

HAL is a multi-disciplinary open access archive for the deposit and dissemination of scientific research documents, whether they are published or not. The documents may come from teaching and research institutions in France or abroad, or from public or private research centers.
L'archive ouverte pluridisciplinaire HAL, est destinée au dépôt et à la diffusion de documents scientifiques de niveau recherche, publiés ou non, émanant des établissements d'enseignement et de recherche français ou étrangers, des laboratoires publics ou privés. 


\title{
Sustainability in Publishing: An Open Access Publisher's View
}

\author{
Martyn Rittman
}

\section{Introduction}

1 Long-term sustainability must be a primary goal for any academic publisher. Without it, knowledge published in journals, books and other formats risks being damaged or lost. If one step in a series of research disappears, it casts doubt on subsequent work. Publishers, as disseminators of verified research, have a responsibility to ensure that published works remain available for future generations.

2 The aim of this paper is to present the point of view of a commercial open access publisher with regards to sustainability in the current publishing landscape. We briefly outline salient points from the history and current state of electronic publishing. The emphasis is on sustainability, and covers both the development of open access and the story of MDPI. We then move on to some current projects arising from our focus on sustainability. Putting sustainability at the heart of publishing activities is an imperative and in the age of electronic publishing new options are emerging that this goal make it easier to achieve. There are concrete steps that can be taken by any academic publisher to ensure the sustainability, preservation, and effective dissemination of knowledge.

3 MDPI sees two primary aspects to sustainability. The first pertains to the preservation of knowledge. Knowledge creation without sustainability makes little sense. New discoveries builds on older research, which must be archived and preserved, or what comes after it does not have a firm foundation. The second strand is MDPI's view that open propagation of knowledge will enhance mankind's future and preserve our environment. The founder of MDPI, Shu Kun Lin, built the company in the belief that advances in research are a key contributor to solving many of the most pressing needs of our age, including over-use of the world's resources and the threat of climate change. The implementation of both strands requires access, discoverability, security, and long-term preservation of 
knowledge. In other words, making all new research immediately available to as many as possible for as long as possible.

\section{The progress of sustainability in electronic publishing}

4 The early stages of electronic publishing took place in the late 1980s and into the 1990s. MDPI was founded in 1996 to preserve chemical samples synthesized in laboratories. Our first journal made the synthesis protocols public in a free, online format, allowing others access to both the chemical itself and the associated methods (Lin 1996). This meant that both rare physical samples and the knowhow to make them was preserved. This was prior to wide use of the term open access. It was one of a number of electronic publishing initiatives, the development of which are charted in several places (Laasko 2012, Morrison, Suber).

5 It took some time for open access to find a way to work at scale. The formation of the public library of science (Plos), initially as an advocacy group and then also as a publisher, was a key step in challenging attitudes within publishing. Its most radical position as a publisher was that editors should not make subjective judgments on which content to publish; instead, they should decide whether work is scientifically sound and leave the question of value until after publication. The ability to do this is a direct result of online publication, since the page counts that limit print journals and force selectivity are not present. The policy supported sustainability by encouraging the publication of research that may otherwise have remained unpublished and undocumented, and therefore unpreserved.

6 At a similar time, in 1999, BioMed Central was launched. It generated revenue through article processing charges (APCs), establishing a business model that could bring financial sustainability and allow for open access journals to operate at larger scales. To date, this has been the primary model for large open access publishers. From a publisher's point of view, APCs are a straightforward solution to funding open access publication. Other options typically require lengthy negotiations with stakeholders and high levels of commitment from large institutions such as funding bodies, libraries, or national agencies. A large number of journals are run by philanthropic grants with no costs to authors, but the grants are often not large enough to permit journals to scale up to hundreds or thousands of papers per year. At the time of writing, the Directory of Open Access Journals (DOAJ) has 8,085 open access journals without APCs and 2,925 journals with an APC, and has historically seen a similar pattern (DOAJ 2016). However, these journals publish only a minority of the total papers: the top 7 largest publishers in DOAJ have published $34 \%$ of the total number of papers and all use APCs as their primary, if not exclusive, source of income.

7 Currently, MDPI offers almost all of its journals under an APC model. In the early years, funding came from grants, the chemical samples projects, some conferences, and donations from individual authors. To facilitate the expansion of MDPI, in 2006 APCs were introduced to all journals (Lin 2006). This has only recently changed with the Knowledge Unlatched project (see below). In responses to a 2013 survey about where MDPI authors find funding to pay APCs, $68 \%$ claimed their money from their institution or directly from their funding body, $20 \%$ funded the APC personally, and the rest used personal discretionary funds. 
The APC model has been adopted by most of the largest traditional publishers, at least under a hybrid model (where an APC can be paid for a paper in a subscription journal) and often in fully open access journals. As has been discussed elsewhere (Kingsley 2014), hybrid open access suffers from a lack of trust that publishers are not charging twice for the same content, so-called double dipping. Prices are also typically higher than journals that only publish open access content.

9 The SCOAP3 project (https://scoap3.org) has sought to provide a way to fully convert the field of particle physics to open access, by raising revenue from libraries, funders, and other organizations. Participating journals are paid from the central fund depending on the number of papers they publish. A similar idea has been taken up by the Knowledge Unlatched project (http://www.knowledgeunlatched.org) which focuses on the humanities and social sciences, which also acts as a distributor of article processing fees using funding collected from participating university libraries. Nine MDPI journals are currently funded by Knowledge Unlatched (MDPI 2018).

\section{The current state of open access}

Open Access currently occupies around 15-20\% and is "nuanced, growing well, but taking share slowly" (Pollock 2018). This suggests reluctance among at least some key stakeholders to make a fuller transition, and that early optimism around a complete switch to open access has not been fulfilled. It has led to reflection about what the future direction should be.

11 From MDPI's point of view, several of the key current themes in academic publishing are as follows:

12 Authors are not incentivized to choose open access when publishing their work. Although many authors express a preference for open access, other considerations-often related to career progression and status-are usually more important this when it comes to decisions on where to publish individual papers. We observe this frequently in author surveys, where open access is not one of the top reasons authors chose an MDPI journal.

13 Citations are frequently used as a proxy for quality. This applies both to quality of the editorial processes (is the journal reputable?) and the value of individual journals (is the standard of research in the journal high?). Editorial board members and potential authors frequently ask about the Impact Factor, and the ratings of scholars, journals and papers are primarily citation-based. In some contexts this may be acceptable in conjunction with other measures, but sole reliance on citation-based metrics reinforces a situation where perceived journal reputation and popularity are of higher value than integrity, transparency, and robust underlying editorial processes.

APCs may not adequately control the costs of publishing. Some hoped that gold open access would create market conditions and drive down prices. Instead, the opposite is often seen, and a higher APC can be interpreted as a mark of quality and reflect well on the prestige of a journal. Amounts over 2000 USD are common and much higher have been reported (see, for example, https://treemaps.intact-project.org/apcdata/openapc/ \#publisher/). MDPI's average APC across all published papers was around 1000 USD in 2017. While publishing entails costs that publishers need to recover, it is not clear whether APCs are the best mechanism to control the flow of money to publishers. Despite APCs being a good option for publishers, as described above, they can prove to be a 
barrier for authors, especially for those in the developing world-even where discounts or fee waivers are available. MDPI's view is that APCs have played an important role in the development of open access to date. However, publishers should be open to alternatives where they provide opportunities to recover costs, can function at scale, and provide appropriate incentives to publish content that meets the standards expected by research communities.

Open science is a growing theme and can help to address issues of preservation. Open science covers open access, open data and open communication (see, for example, the European Commission's open science monitor https://ec.europa.eu/research/openscience/ index.cfm?pg=home\&section=monitor). Thus far, we have not seen a significant move from authors towards more availability of data. However, this may change with the launch of the European Open Science Cloud and similar initiatives. The concept of preprints (research articles posted and archived before peer review has been completed) is a growing one and has expanded in recent years from mathematics, physics and economics (through arXiv and SSRN) to life sciences and other subjects. In 2016, MDPI launched Preprints.org as a multidisciplinary preprint server, which published its 3000th article in February 2018. While still a minority of MDPI authors choose preprints, we have seen increasing awareness and participation. We also operate Sciforum.net as a platform for recording alternative methods of research communication, including comments on published papers, and conferences.

To support efforts for global development, MDPI publishes the title Sustainability, a broadscope journal looking at aspects of sustainability in many different areas. It also runs the World Sustainability Forum and sponsor the World Sustainability Award (http:// sciforum.net/conference/

wsf-6/page/76), operated through the MDPI Sustainability Foundation (http:// wsforum.org/foundation). Sustainability is included in the scope of many MDPI journals, fulfilling the role we see to address issues of development and resource management through research and technology, and to support the United Nations Sustainable Development Goals.

\section{Moving forward}

The present does not feel like a time of consolidation for open access publishers. While the concept of open access is now well-known and generally accepted, there are challenges to improve business models, innovate technology, and increase the proportion of papers published in open access format. The expansion of open access alone is a step forward to achieving greater sustainability in publishing, however here we list some of the other initiatives MDPI is undertaking have a link with sustainability.

First, MDPI support umbrella initiatives that work towards sustainability. These include the UN Sustainable Development Goals, the Jussieau call (http://jussieucall.org), the Declaration on Research Assessment (DORA, https://sfdora.org), and the Initiative for Open Citations (https://i4oc.org). In particular, the Jussieau call commits MDPI to actively explore models other than APCs.

Second, MDPI invests in alternative business models and the preservation of nontraditional output. This includes Knowledge Unlatched, Preprints.org, online conferences (through sciforum.net), and running journals with non-traditional scopes or editorial 
processes. Our journals include Data-publishing descriptions of collected data sets; Challenges-presenting hypotheses and introducing key research questions; Methods and Protocols-for the description of research techniques; and $J$ and Sci-two broad-scoped journals aimed at providing rapid peer review based solely on scientific soundness, with Sci offering post-publication peer review. We have also recently launched Encyclopedia, a scholarly online encyclopedia to offer reference information on the latest research findings and hypotheses.

Third, we support aspects of open science, including preprints, open peer review, and open IDs (in particular ORCID). We have ensured that our journal requirements comply with at least level I of the TOP guidelines (https://cos.io/our-services/top-guidelines/). Scilit.net is an effort to index all academic articles, indicate which are open access, and allow scholars and others a free interface to find relevant articles.

21 Fourth, long-term preservation is achieved for our journals through CLOCKSS (https:// www.clockss.org/

clockss/ and the Swiss National Library's e-Helvetica archive (https://www.ehelvetica.nb.admin.ch/pages/main.

jsf). This ensures that, even if MDPI does not achieve financial sustainability in the future, its published research will remain available. This is an action that any responsible publisher should take.

We firmly believe that open scholarship and infrastructures can support a healthy publishing industry that collaborates with the research communities that it serves and is not viewed as exploitative. Sustainability must remain a key value as we look for ways to better achieve this outcome. MDPI in neither unique nor comprehensive with the initiatives described above. We invite other publishers to join in working towards a sustainable research ecosystem, following the tradition of close cooperation with each other and the research communities we serve. Through these efforts and sharing of best practices, we can ensure the preservation and effective propagation of knowledge, and a better future for the world in which we live.

\section{BIBLIOGRAPHY}

\section{References}

Lin, S.-K. (1996). “A Good Yield and a High Standard.” Molecules. 1: 1-2.

Lin, S.-K., McPhee D.J., \& Muguet, F.F. (2006). “Open Access Publishing Policy and Efficient Editorial Procedure." Entropy. 8: 131-133.

Suber, P. Timeline of the Open Access Movement. Available online at https://dash.harvard.edu/ bitstream/handle/1/4724185/suber_timeline.htm (accessed 28 March 2018)

Laakso, M., \& Björk, B.-C. (2012). "Anatomy of open access publishing: A study of longitudinal development and internal structure." BMC Medicine, 201210: 124. 
Morrison, H. Dramatic Growth of Open Access Series. Available online: http:// poeticeconomics.blogspot.com/2006/08/dramatic-growth-of-open-access-series.html (accessed 29 March 2018)

DOAJ (2016). (UPDATED) Historical APC Data from before the April upgrade. Available online at: https://blog.doaj.org/2015/05/11/historical-apc-data-from-before-the-april-upgrade/ (accessed on 29 March 2018).

Kingsley, D.A. (2014). "Paying for Publication: Issues and Challenges for Research Support Services." Australian Academic \& Research Libraries, 45: 4, 262-281.

MDPI (2018). Knowledge Unlatched Funding for MDPI Journals as of 2018. Available online: http:// www.mdpi.com/about/announcements/1023 (accessed 19 March 2018)

Pollock, D. (2018). News \& Views: 2018 Outlook. Available online: https://deltathink.com/newsviews-2018-outlook/ (accessed on 19 March 2018).

\section{ABSTRACTS}

Sustainability is an essential part of the work of publishers. Here, the view of an open access publisher, MDPI, is presented with regards to sustainability within publishing. MDPI's understanding of sustainability is given and some of the concrete actions it leads to. These include supporting umbrella initiatives, exploring alternative business and editorial models, elements of open science, and ensuring the long-term sustainability of published content. Our aim is to demonstrate actions that could be taken by other publishers and to invite dialog with the broader research community for how a large open access publisher can contribute to a sustainable knowledge ecosystem.

\section{INDEX}

Keywords: open access, sustainability, scholarly publishing

\section{AUTHOR}

\section{MARTYN RITTMAN}

MDPI AG, St. Alban-Anlage 66, 4052 Basel, Switzerland

rittman@mdpi.com

(corresponding author) 